\title{
The Design of Portable Equipment for Greenhouse's Environment Information Acquirement Based on Voice Service
}

\author{
Xin Zhang ${ }^{1,2}$, Xiaojun Qiao ${ }^{1}$, Wengang Zheng ${ }^{2, *}$, Cheng Wang ${ }^{2}$, and Yunhe Zhang ${ }^{2}$ \\ ${ }^{1}$ National Engineering Research Center for Information Technology in Agriculture, 100097, \\ Beijing, China \\ ${ }^{2}$ Beijing Research Center for Intelligent Agricultural Equipment, 100097, Beijing, China \\ \{zhangx, qiaoxj, zhengwg, wangc, zhangyh\} @nercita.org.cn
}

\begin{abstract}
For settling the problem of acquiring environment parameters quickly and responding in time in greenhouse which has low ability of auto-controlling environment. This paper designed a voice service system which was used in greenhouse for environment information collecting. This equipment can acquire and analyze the parameters of temperature, humidity, illumination, dew point temperature, soil temperature, soil humidity. And it offered alarm and environment controlling suggestion by voice. This equipment achieved data acquiring, storage, displaying and voice service by MCU msp430 and voice chip PM50S100. Expert knowledge which had simple decision logic was embedded in this system. This equipment offered simple voice service based on the collecting data in greenhouse. And it had advantages of convenience operation, low power consumption through the test in greenhouse.
\end{abstract}

Keywords: greenhouse, environment parameters, voice service, portable equipment.

\section{Introduction}

The main symbol of agriculture modernization's level is the facilities agriculture's development which uses protected agriculture as the main representative. Facilities agriculture in China has made rapid development in recent years. And it plays an important role to improve farmer's incomes and quality of life. But at present, simple structure greenhouses such as solar greenhouse \& plastic greenhouse which are widely used in China. Most of these greenhouses have backward technology, low levels of machinery and automation. The current advanced information technology is not used in these greenhouse deeply. Facilities production remains in experience management, unscientific \& non-standard management. All these situations are seriously affected the yield and efficiency. Most of information collection instruments in greenhouse environment are expensive, un-flexible and single parameter collection. But equipments with more parameters acquisition function has large size, high power

\footnotetext{
${ }^{*}$ Corresponding author.
} 
consumption and bring the inconvenience in installation and maintenance. All these equipments also need personal view and recording by operators. When many equipments are used in large-scale greenhouses, it is needed for additional staff and long time observation which may cause nervous fatigue and error record[1]. The voice communication technology combines with the environment information collection equipment is a new direction of greenhouse environment collection \& controlling in intelligence and information. The technology which mentioned upon is used in many fields. Agricultural consulting and calling business has matured in Europe and United States[2]. One of U.S. research institution designed a soil moisture meter with wireless voice service which could dial to user's cell phone to send alarm information when the data exceeded the setting[3]. Agricultural calling center base on mid-ware which designed by Beijing Institute of machinery had made expert system in networks, remote consultation and calling center to come true. And built a model which could bring out 24 hour pest diagnosis, advisory services. Beijing Academy of Agriculture and Forestry had similar system[4][5]. Bo Jing, Xiaojun Qiao proposed and developed the voice warning system for the environmental information in greenhouse[1]. Caili designed a voice-alarm system for greenhouse base on DDE and FCS technique[6]. The applications above focused on passive network calling and initiative alarm. But there are lack of deep study in the expert knowledge and smart voice technology which integrated with portable greenhouse environment information acquisition device. It is urgent need to design low price and practical product which rely on the voice service technology.

This paper has designed a portable equipment for greenhouse's environment information acquirement base on voice service. This equipment is cost-effective, easy to use, multi-parameters measurement and can use voice to guide the different cultural level farmers to manage greenhouse production according to different crop growth stages' demands. Promote the use of this product can effectively increase the level of greenhouse production and management, and give full play to the potential of greenhouse production.

\section{Design Ideas Overview}

As figure 1 showed greenhouse site needs to measure the common environment parameters accurately by external ways. Temperature \& humidity, soil temperature, light etc. are the key parameters in greenhouse management. Solar radiation shield is used for measuring temperature $\&$ humidity avoiding solar radiation and bad weather. The portable equipment obtains and stores data from sensors according to the setting time interval. And data were showed in the liquid crystal displayer at the same time. Simple logic expert knowledge table was integrated in the device. So it could guide farmer by voice. Many communication methods were used in this system. RS485 /Internet/Wireless achieved the greenhouses monitoring by network. When used USB to communication with the $\mathrm{PC}$, this equipment as a portable device to measure the data from greenhouse by moving. This paper focus on the design of sensor, data gathering equipment and PC software. 


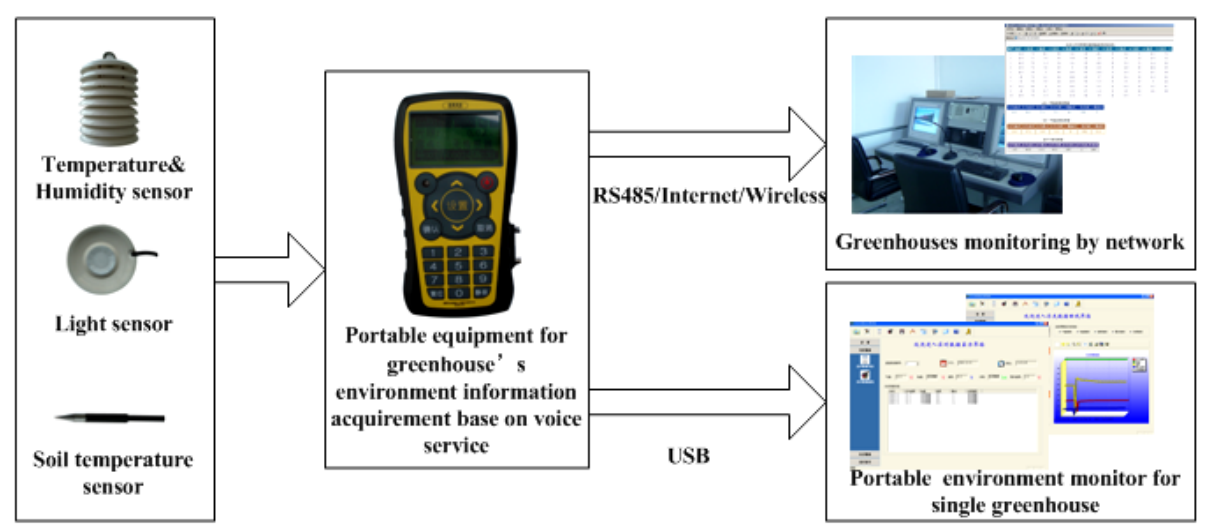

Fig. 1. Structure of portable equipment for greenhouse's environment information acquirement base on voice service

\section{The Design of Underlying Hardware and Software}

\subsection{The Structure of Hardware}

The hardware design used ultra-low power MCU MSP430F149 which had 60KB flash, 2KB RAM, two 16bit timers, eight channels 12bit A/D converter, USART/SPI port and so on[7]. $128 * 64$ dots matrix LCD was used for displaying the sensor data and setting menu. Real time clock chip DS1302 provided clock and date for system. Flash data storage memory chip AT45DB081 provided 1Mbytes space for store the data of environment[8]. $4 * 5$ touch panel was used for system setting. Embedded real audible voice module (PM50S100) was used for voice service. Charge chip LTC4055
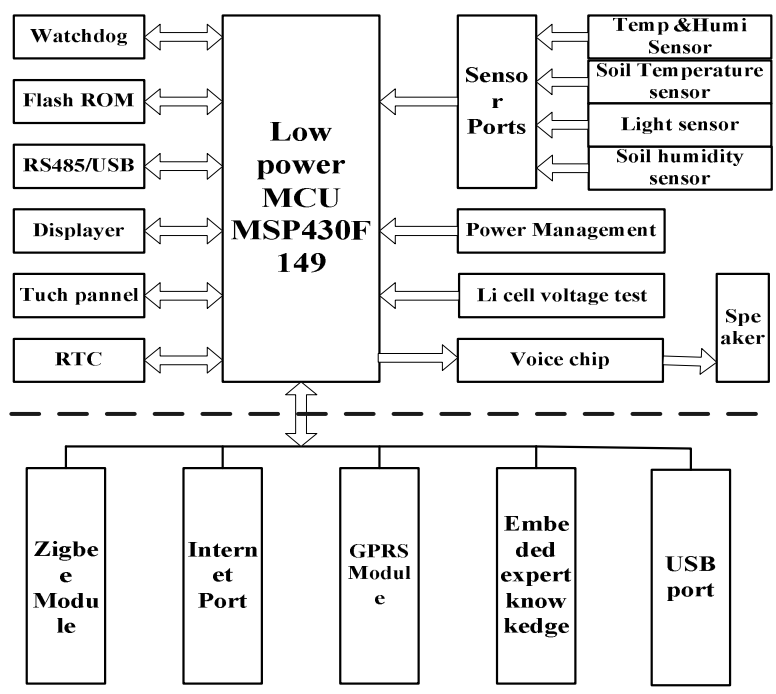

Fig. 2. Structure of hardware 
charged for the inside $2 \mathrm{~A}$ lion battery . NCP500 provided 3.3V voltage for the system. Ti's chip TPS2044 was used for managing the power of sensors. Zigbee module, GPRS module, Internet module, usb and RS485 could used in this equipment. User can choose the suitable communication ways for application. Some kinds of crop production's expert knowledge were embedded in the ROM chip FM24CL64. Temperature and humidity sensor SHT11 was used in this system. This sensor integrated sensor element plus signal processing on a tiny foot print and provide a fully calibrated digital output. The applied CMOSens ${ }^{\circledR}$ technology guarantees excellent reliability and long term stability. Both sensors are seamlessly coupled to a 14bit analog to digital converter and a serial interface circuit. DS18B20 encapsulated in stainless steel was used for measuring the soil temperature. Programmable light to frequency converter chip TSL230B was used for measuring the light.

\subsection{Voice Processing Circuit}

This design used smart voice chip PM50S100 which was produced by ATVOC company. Compared with the ISD's voice chip, PM50 had better tone quality and lower price. This chip was made up of voice MCU and Flash RAM. 100 seconds playback function was enough for this equipment. Actual circuit is showed in Figure 3. MSP430F149 sent instruction to PM50 for controlling the voice file by series port. Voice signal could through the op amp LM386 for output or PWM mode was used for driving $8 \mathrm{ohm} 0.5 \mathrm{~W}$ speaker directly[9].

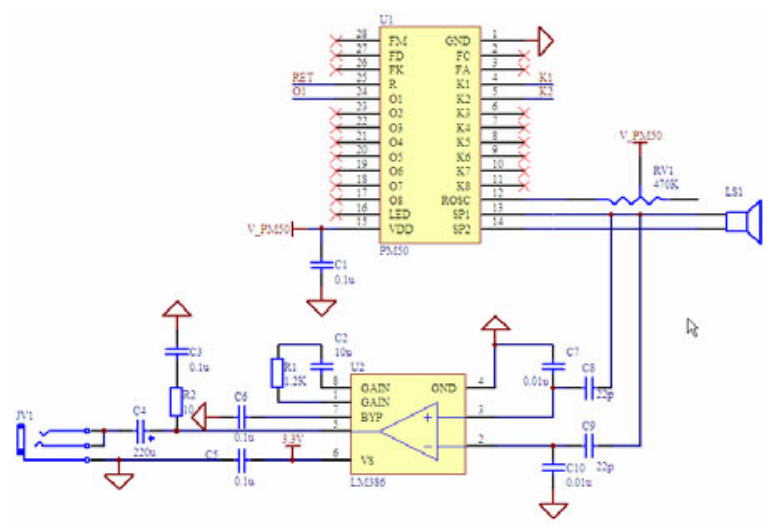

Fig. 3. Voice processing circuit

Voice files were recorded by professional recording equipment. Software Cool editor edited the voice files and divided file into sections which were programmed to voice chip by the program copier easily. Voice files were cheesed from greenhouse environment control equipments, methods, alarm mode, common voice phrases and sentence in solar greenhouse and plastic greenhouse production. Part of sound logic as follows.

- IF Tn> Tmax then voice file "baby cry sound", "It's too hot, open the windshield quickly".

- IF Tn< Tmin then voice file "baby cry sound", "It's too cold, close the windshield quickly". 
Tn is the temperature now, Tmax is the setting maximum temperature, Tmin is the setting minimum temperature.

\subsection{Integrated Design of Expert Knowledge}

This design choosed the representative crops which often grow in greenhouse. These crops were also classified into six kinds, and coded in binary. (See the Table 1)

Table 1. Actual crops' kings and codes

\begin{tabular}{ccc}
\hline Crop kinks & Code & Crops \\
\hline Eggplant & 0001 & Tomato, Pepper \\
Melon and fruit & 0010 & Muskmelon, Cucumber \\
Leafy & 0011 & Fennel, Celery \\
Fruit trees & 0101 & Grape, Pear \\
Flowers & 0110 & China rose, Chrysanthemum \\
\hline
\end{tabular}

The 64Kbit FRAM FM24CL64 used for storing the expert knowledge[10]. User can choose different crops and growth stages from the expert knowledge. The data in the expert knowledge table was also changed by user's experience and actual environment. FAT store structure was used for storing the expert knowledge. Expert knowledge divided the crops into eggplant, melon and fruit, leafy, beans, fruit trees, flowers. The RAM address 0x0000-0x001F was used as the first index of partition which was showed in Table 2. The equipment get the actual crop's store address through index address in Table 2. Actual crop's store information was store in the second index of partition (partition's address is 0x0020-0x01FF). Table 3 showed part of actual crop's store information. The stages in Table 3 means that the number of stages. promote germination period, germination period, seeding period, transplant period, after transplant period, one week before planting, planting to seeding stage, growth stage, flowering fruit setting period, expanding fruit stage, harvest storage period were used in expert knowledge[10]. Table 4 showed that the actual data in promote germination period. All the tables showed that the physical address was memory's address, and the number is the content stored in this address.

The expert knowledge table which mentioned above was managed by two levels address index method. This method made the expert knowledge's embedded application conveniently because it searched data easily and saved the memory space.

Table 2. The first index of partition $(0 \mathrm{x} 0000-0 \mathrm{x} 001 \mathrm{~F})$

\begin{tabular}{c|cccc}
\hline Physical Address & 0x0000 & 0x0001 & 0x0002 & 0x0003 \\
Note & eggplant & kinds & Address. H & Address. L \\
Number & 0x01 & 0x02 & 0x00 & 0x20 \\
\hline
\end{tabular}

Table 3. The second index of partition (0x0020-0x00FF)

\begin{tabular}{c|cccc}
\hline $\begin{array}{c}\text { Physical Address } \\
\text { Note }\end{array}$ & 0x0020 & 0x0021 & 0x0022 & 0x0023 \\
Number & tomato & stages & Address. H & Address. L \\
& 0x01 & 0x04 & 0x02 & 0x00 \\
\hline
\end{tabular}


Table 4. Part of parameter table of expert knowledge

\begin{tabular}{|c|c|c|c|c|c|c|c|c|c|}
\hline $\begin{array}{l}\text { Physical } \\
\text { Address } \\
\text { Note } \\
\text { Number } \\
\end{array}$ & $\begin{array}{c}0 \mathrm{x} 0280 \\
\text { germination } \\
0 \times 01 \\
\end{array}$ & $\begin{array}{c}\text { 0x0281 } \\
\text { Tdmax.L } \\
16\end{array}$ & $\begin{array}{c}0 \mathrm{x} 0282 \\
\text { Tdmax.H } \\
25 \\
\end{array}$ & $\begin{array}{c}0 \times 0283 \\
\text { Tdmin.L } \\
16\end{array}$ & $\begin{array}{c}0 \mathrm{x} 0284 \\
\text { Tdmin.H } \\
15\end{array}$ & $\begin{array}{c}0 \mathrm{x} 0285 \\
\text { Tnmax.L } \\
16 \\
\end{array}$ & $\begin{array}{c}0 \mathrm{x} 0286 \\
\text { Tnmax.H } \\
25 \\
\end{array}$ & $\begin{array}{c}\text { 0x0287 } \\
\text { Tnmin.L } \\
15\end{array}$ & $\begin{array}{c}0 \mathrm{x} 0288 \\
\text { Tnmin.H } \\
16\end{array}$ \\
\hline $\begin{array}{c}\text { Physical } \\
\text { Address } \\
\text { Note } \\
\text { Number }\end{array}$ & $\begin{array}{c}\text { 0x0289 } \\
\text { Hdmax } \\
60 \\
\end{array}$ & $\begin{array}{c}\text { 0x028A } \\
\text { Hdmin } \\
80 \\
\end{array}$ & $\begin{array}{c}\text { 0x028B } \\
\text { Hnmax } \\
60 \\
\end{array}$ & $\begin{array}{c}\text { 0x028C } \\
\text { Hnmin } \\
80 \\
\end{array}$ & $\begin{array}{l}\text { 0x028D } \\
\text { Lmin } \\
2\end{array}$ & $\begin{array}{c}\text { 0x028E } \\
\text { Lmax } \\
30 \\
\end{array}$ & $\begin{array}{c}\text { 0x028F } \\
\text { STdmax.L } \\
16\end{array}$ & $\begin{array}{c}\text { 0x0290 } \\
\text { STdax.H } \\
36\end{array}$ & $\begin{array}{c}\text { 0x0291 } \\
\text { STdmin.L } \\
10\end{array}$ \\
\hline $\begin{array}{c}\text { Physical } \\
\text { Address } \\
\text { Note } \\
\text { Number }\end{array}$ & $\begin{array}{c}\text { 0x0292 } \\
\text { STdmin.H } \\
16\end{array}$ & $\begin{array}{c}\text { 0x0293 } \\
\text { STnmax.L } \\
16\end{array}$ & $\begin{array}{c}\text { 0x0294 } \\
\text { STnmax.H } \\
26\end{array}$ & $\begin{array}{c}\text { 0x0295 } \\
\text { STnmin.L } \\
10\end{array}$ & $\begin{array}{c}\text { 0x0296 } \\
\text { STnmin.H } \\
16\end{array}$ & $\begin{array}{l}\text { 0x0297 } \\
\text { SHmin } \\
\text { obligate }\end{array}$ & $\begin{array}{l}\text { 0x0298 } \\
\text { SHmax } \\
\text { obligate }\end{array}$ & $\begin{array}{l}- \\
--- \\
---\end{array}$ & $\begin{array}{l}- \\
--- \\
---\end{array}$ \\
\hline
\end{tabular}

\subsection{Low Power Embedded Software Design}

As a portable equipment whose sensors' data gathered, LCD displayer, background light, voice output had large power consumption. All these devices were not suited working for a long time. Work mode should been managed by software and hardware. The sensors' power must be closed when they did not used. LCD displayer was in doze mode when there were no data refreshed or keypad acted. The part of voice output's working mode was divided into real time, compare, alarm, close mode. All these modes were used in equipment could lower the power consumption.

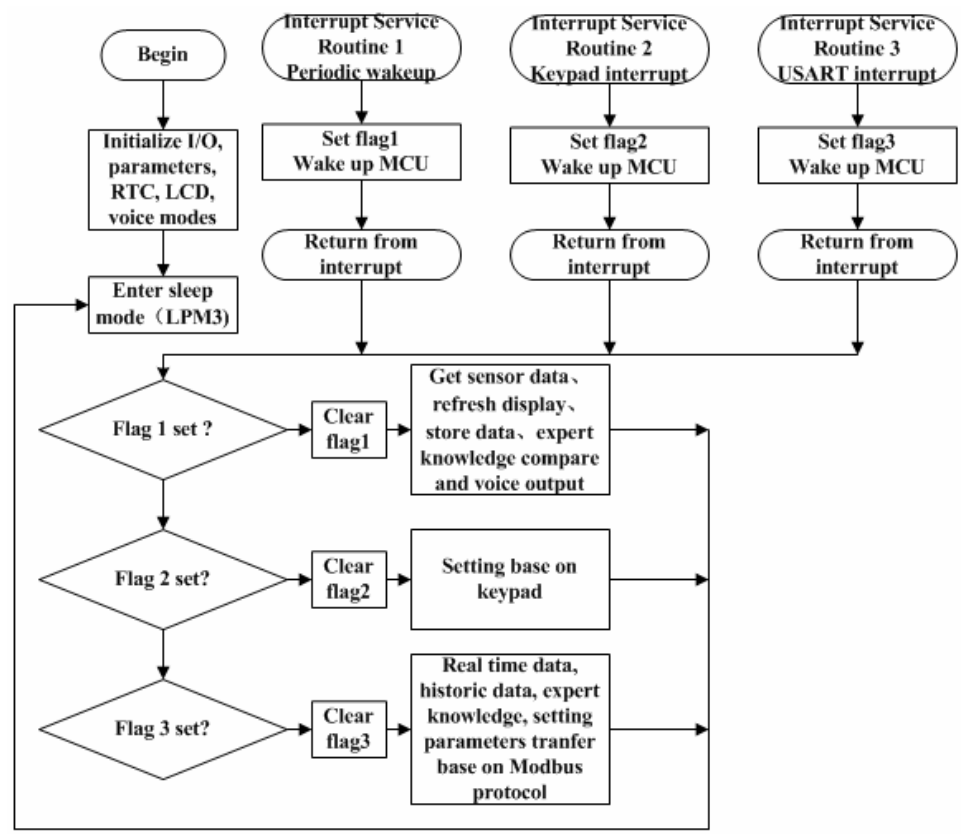

Fig. 4. The structure of low power software 
The structure of low power software was showed in Figure 4. The program came into low power mode after it started and initialize the system. The flags were changed in the interrupt service routine. Subroutines were called by flags' judgment in main routine. This software coding mode base on interrupt-wake up could lower more power consumption[11].

\section{PC Software Design}

Base on the design of the underlying hardware and software. The information's analysis \& management software was designed on PC platform. This PC software could get the environment information which gathered by the hardware. Many kinds of communication ways were used in the software. The data collected could be showed by figures and tables. Search and statistical analysis service were also provided in the PC software.

Software design based on the operation system Windows XP Professional. Programming language was Visual $\mathrm{C}++$ 6.0. The software design followed the below outline.

- Good compatibility. Software was designed by module method. Other module could not affected when one of module was changed.

- Fine interface. Toolbar and pull-down menu were used in the software. User did not study the usage of the software. It is easy to operating the software by click some icons.

- Simple operation. Each operation function was distributed by user's operate habit.

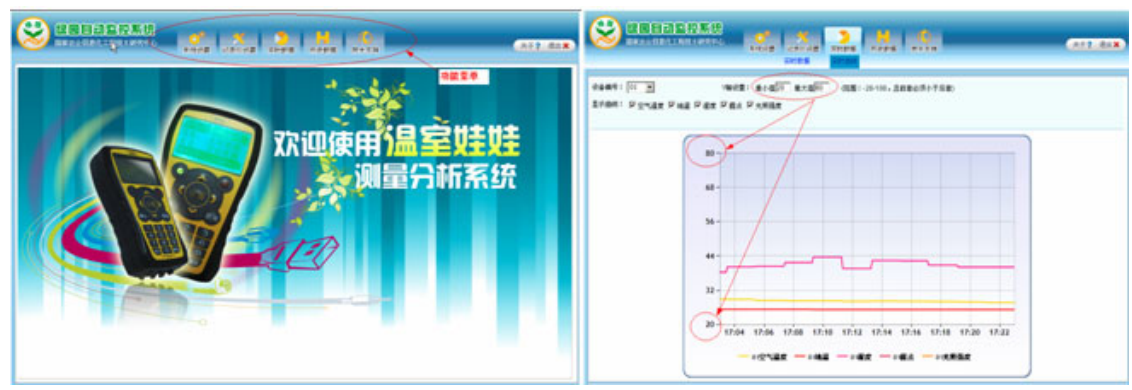

Fig. 5. Part of interface of PC software

\section{The Test of Performance and Function}

\subsection{The Test of Sensors' Accuracy}

The sensors used in this equipment were tested and calibrated by National Standards Research Center which belong to National Bureau of Quality and Technical Supervision. The sensors' performance parameters were showed in Table 5.

Took temperature and humidity testing as example. Calibration and test followed the test rules of JJG368-2000, Copper-copper nickel thermocouple was used for calibrating the temperature. Constant temperature and humidity box MFT-434A provide 
Table 5. Sensors' performance parameters

\begin{tabular}{l|llc}
\hline \multicolumn{1}{c|}{ Sensors } & Resolution & Accuracy & Range \\
\hline Temperature & $0.1^{\circ} \mathrm{C}$ & $\pm 0.1^{\circ} \mathrm{C}$ & $-40^{\circ} \mathrm{C} \sim 80^{\circ} \mathrm{C}$ \\
Humidity & $0.1 \% \mathrm{RH}$ & $\pm 2 \% \mathrm{RH}$ & $0 \sim 100 \% \mathrm{RH}$ \\
Soil Temp. & $0.1^{\circ} \mathrm{C}$ & $\pm 0.2^{\circ} \mathrm{C}$ & $-40^{\circ} \mathrm{C} \sim 80^{\circ} \mathrm{C}$ \\
Dew point & $0.1^{\circ} \mathrm{C}$ & $\pm 1{ }^{\circ} \mathrm{C}$ & $-40^{\circ} \mathrm{C} \sim 80^{\circ} \mathrm{C}$ \\
Light & $0.1 \mathrm{Lux}$ & $\pm 5 \%$ & $0 \sim 200000 \mathrm{Lux}$ \\
\hline
\end{tabular}

stable temperature and humidity environment. Precision equipment M4/1111H was used for testing dew point temperature. Calibrate the humidity followed the rules of JJF1076-2001. The humidity generator M4/1311DR provided stable environment. Dew point temperature calibration followed the rule of JJG499-87[12]. Calibration result was showed in Table 6. Table 6 showed the sensors were suitable for greenhouse measurement.

Table 6. The data of calibration and test

\begin{tabular}{c|ccccccccc}
\hline \multirow{2}{*}{ Num. } & \multicolumn{3}{|c}{ Temperature $\left({ }^{\circ} \mathrm{C}\right)$} & \multicolumn{3}{c}{ Humidity $(\% \mathrm{RH})$} & \multicolumn{3}{c}{ Dew point $\left({ }^{\circ} \mathrm{C}\right)$} \\
\cline { 2 - 10 } & Standard & Measure & Amend & Standard & Measure & Amend & Standard & Measure & Amend \\
\hline $\mathbf{1}$ & -10.5 & -10.5 & 0.0 & 10.4 & 11.0 & -0.6 & -11.7 & -10.8 & -0.9 \\
$\mathbf{2}$ & 0.0 & 0.0 & 0.0 & 20.6 & 21.3 & -0.7 & -2.9 & -3.0 & -0.1 \\
$\mathbf{3}$ & 10.1 & 10.1 & 0.0 & 30.5 & 31.3 & -0.8 & 2.5 & 2.3 & +0.2 \\
$\mathbf{4}$ & 20.9 & 20.8 & +0.1 & 40.6 & 40.3 & +0.3 & 6.6 & 6.4 & +0.2 \\
$\mathbf{5}$ & 30.7 & 30.6 & +0.1 & 50.5 & 50.4 & +0.1 & 9.8 & 9.9 & -0.1 \\
$\mathbf{6}$ & 40.7 & 40.6 & +0.1 & 60.5 & 60.0 & +0.5 & 12.5 & 12.7 & -0.2 \\
$\mathbf{7}$ & 50.6 & 50.5 & +0.1 & 69.3 & 69.4 & -0.1 & 14.6 & 14.8 & -0.2 \\
$\mathbf{8}$ & 60.3 & 60.4 & -0.1 & 78.5 & 78.5 & 0.0 & 16.5 & 16.7 & -0.2 \\
$\mathbf{9}$ & & & & 88.8 & 87.8 & +1.0 & 18.5 & 18.4 & +0.1 \\
\hline
\end{tabular}

\subsection{Function Test}

The equipment was tested in greenhouse for a long time. The M.T.B.F. is over one year. It's stability and adaptability could meet the greenhouse's production acquirement. Test picture and real time data were showed in Figure 6.

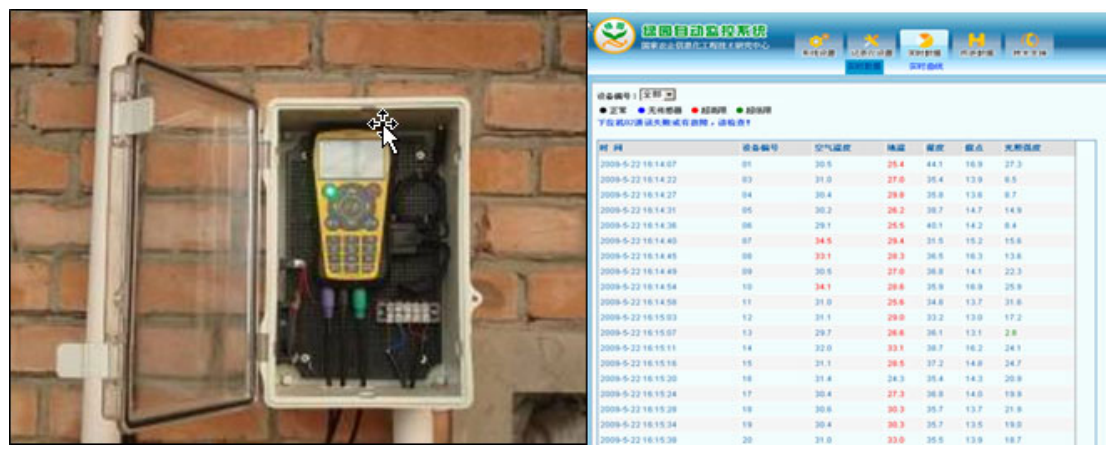

Fig. 6. Test and real time data pictures 


\section{Conclusions}

This design provided voice service base on the collection of greenhouse's key environment information. And expert knowledge table was embedded in the equipment. It could guide the different cultural level farmer to greenhouse production management according to different crop growth stages' demands by voice. Compare with the technology in existence. The design had a lot of characteristics and advancements. (1) Portable multi-parameter measurement. It could measurement temperature .humidity, dew point temperature, illumination, soil temperature at the same time. (2) Voice output. It could provide management knowledge and the gathered parameters by voice. (3) Good adaptability in greenhouse's environment. (4) High cost performance. It's price was one third to one second of production which had similar function. So this design had good prospect in greenhouse production.

Acknowledgement. It is a project supported by national 863 project "The application and construction of facilities agriculture's production technology system" (2006AA10A311), and national supported project "The design and application on integration of management \& control of facilities agriculture technology" (2008BAD6B00).

\section{References}

1. Jing, B., Qiao, X., Wang, C.: Development of voice warning system for the environmental information in greenhouse. Transactions of the CSAE 20(4), 209-211 (2004)

2. Qi, H.: The design and realization on voice service system orienting cow. The college of north-east agriculture (2006) (in Chinese)

3. Li, C., Sheng, J.: The design of voice alarm system. Technology of electric 7, 51-54 (2001) (in Chinese)

4. Zhang, J., Tian, Z.: The construction of agriculture calling center base on middle ware. The dynamic of telecom decision, 46 (2003) (in Chinese)

5. Song, J.: The past, now and future of calling center. Computer World (5), pp.B1-B3 (2001) (in Chinese)

6. Cai, L., Tan, Z.: Design of the voice-alarm system for greenhouse base on DDE and FCS technique. The study of No.6, pp.167-169 (2007) (in Chinese)

7. Sheng, J., Yang, Y.: The elements of 16bit ultra-low power MCU MSP430. Beijing University of Aeronautics and Astronautics Press (2008) (in Chinese)

8. Atmel.:The datasheet of 8Megabit 2.7-volt Only Serial DataFlash AT45DB081. Rev.0870B-10/98

9. Atvoc:The datasheet of PM50 series smart voice chip, http: / / www . atvoc.com

10. Qiao, X., Zhang, T.: High performance planting technology of greenhouse's vegetables and flowers. Beijing Sanxia Press (2008)

11. TEXAS INSTRUMENT. Application Report of MSP430 Software Coding Techniques. SLAA294-MARCH (2006)

12. Certificate of National standards Research Center Number:2005-19-006-009 